\title{
Condições socioeconômicas de pescadoras artesanais e agricultoras familiares: o caso do lago Maicá, Santarém, Brasil
}

\section{Socioeconomic conditions of artisan fisherwomen and female family farmers: the case of the Lake Maicá, Santarém, Brazil}

Wandicleia Lopes de Sousa - Doutoranda no Programa de Pós-Graduação em Sociedade, Natureza e Desenvolvimento (PPGSND) da Universidade Federal do Oeste do Pará (UFOPA).E-mail: wandicleia@hotmail.com

Elizabete de Matos Serrão - Mestra em Recursos Aquáticos Continentais Amazônicos pela Universidade Federal do Oeste do Pará (UFOPA). E-mail: elizabetematos.stm@hotmail.com

Thiago Almeida Vieira - Pós-Doutor pela Universidade do Algarve (UAlg). Professor da Universidade Federal do Oeste do Pará (UFOPA). E-mail: thiago.vieira@ufopa.edu.br

\section{Resumo}

O estudo objetivou descrever as condições socioeconômicas das pescadoras artesanais e agricultoras familiares dos bairros Maicá e Pérola do Maicá, em Santarém, Pará, Brasil. A pesquisa se deu a partir de uma abordagem qualiquantitativa. A média de idade das pescadoras artesanais e das agricultoras familiares foi de $48,4( \pm 8,6)$ anos e $46,3( \pm 6,4)$ anos (respectivamente). A maioria é oriunda de comunidades rurais de Santarém e das cidades vizinhas e possui apenas o ensino fundamental incompleto, o que corrobora a fragilidade do acesso à educação nessas comunidades. Além disso, as mulheres descreveram que vivem em ambiente com infraestrutura vulnerável e de pouco acesso às políticas públicas. Possuem renda média de $\mathrm{R} \$ 1.124,50$ entre as pescadoras, e entre as agricultoras uma média de R\$ $1.800,30$. Essa pesquisa subsidia discussões sobre modelos de desenvolvimento adotados na região amazônica e para elaboração de políticas públicas que ordenem o desenvolvimento social, econômico e ambiental desse território.

\section{Palavras-chave}

Atividade produtiva. Populações tradicionais. Protagonismo Feminino. Amazônia.

\begin{abstract}
This study describes the socioeconomic conditions of artisanal fishers and family farmers from the Maicá and Pérola do Maicá neighborhoods, in Santarém, Pará, Brazil. The research was based bith on a qualitative and quantitative approach. The average age of artisanal fishers and family farmers is 48.4 ( \pm 8.6$)$ years and $46.3( \pm 6.4)$ years (respectively). Most come from rural communities surrounding Santarém and neighboring cities, did incomplete primary education, which corroborates the fragility of access to education in these communities. Additionally, women described living in an environment with vulnerable infrastructure and poor access to public policy. They have an average income of $\mathrm{R} \$$ 1,124.50 among fishers, and among farmers an average of $\mathrm{R} \$ 1,800.30$. This research supports discussions on the development models to be thought of the population in the Amazon region and the elaboration of public policies that order the social, economic and environmental development of this territory.
\end{abstract}

\section{Keywords}

Productive activity. Traditional populations. Female protagonism. Amazonia. 


\section{INTRODUÇÃO}

Na região amazônica, a agricultura familiar e a pesca artesanal desenvolvidas nas comunidades por populações tradicionais mostram-se semelhantes em aspectos como: cultura, religião, saberes, identidades e, principalmente, forma de se organizar, fatores que envolvem as famílias, com fins produtivos, visando ao autoconsumo e à geração de renda, a partir do uso de recursos naturais, o que pode contribuir na transformação do espaço onde habitam. De modo especial, assemelham-se também na ausência de políticas públicas que visem valorizar o esforço produtivo dos agricultores familiares e pescadores artesanais (DELGADO, 2001).

Em Santarém, a aptidão econômica é diversificada. Uma atividade que desenvolve função fundamental na geração de emprego e renda é a pesca artesanal, além de ser responsável pela garantia do alimento para a maioria das famílias. A sua localização estratégica, às margens dos rios Amazonas e Tapajós, torna-a um dos principais polos de desembarque pesqueiro do Baixo Amazonas, devido ao potencial natural existente na região de várzea (FURTADO, 1990; BATISTA; ISAAC; VIANA, 2004). Encontra-se, ainda, entre os cinco principais mercados, garantindo a maior parte de processamento de pescado da região, incluindo Manaus e Belém (MARTINS, 2009).

A agricultura familiar na região de Santarém também se destaca pela produção de alimento e geração de emprego. A Cooperativa dos Produtores Rurais de Santarém (Cooprusan) comercializa polpas de frutas (cupuaçu, maracujá, cacau, carambola, abacaxi acerola, caju, goiaba, jaca, manga, murici e taperebá), além de produtos de hortifruti que atendem a uma rede de supermercados da cidade e ao Programa Nacional de Alimentação Escolar (Pnae).

Entre as cidades da região do Baixo Amazonas, Santarém tornou-se lócus de investimentos de grande e médio porte, sendo eles os principais causadores de degradação ambiental e socioeconômica (SILVA, 2014). A nova injeção de capital deu-se em função da cidade estar dentro do arco norte, onde a rota de saída de grãos pelo Norte inclui a BR-163 e as hidrovias do Tapajós e do Amazonas nos próximos anos, tornando a cidade um local em potencial para investimentos de países como a China, o maior importador de soja do Brasil (MORENO, 2015).

Os bairros escolhidos para o estudo estão localizados às margens do lago Maicá, que é "um complexo ecossistema composto por ilhas e uma parte de terra firme, que sofrem pequenas inundações decorrentes da cheia dos igarapés lá existentes, e do lago que o circunda" (VIEIRA, 2013, p. 5). É um ambiente extremamente importante considerado como área-chave, disponibilizando 
diversos habitats (refúgios/proteção/forrageio) com condições adequadas para o crescimento de diversas espécies de peixes migradoras e sedentárias de interesse econômico (SERRÃO et al., 2019), como também de quelônios, répteis, aves, além da flora que conta com uma biodiversidade de plantas aquáticas, típicas da região amazônica que possuem grande importância ambiental para o ecossistema amazônico (VAZ, 2016).

É um espaço que vem passando por recentes transformações que podem causar mudanças na paisagem e no ecossistema, além de prejudicar o modo de vida das populações tradicionais quilombolas, indígenas, pescadores e agricultores familiares que habitam essa região. Estes fatos podem ser observados na mudança da paisagem decorrente dos investimentos nos últimos anos, uma vez que essas atividades econômicas acarretam prejuízos aos ecossistemas da região e aceleram processos como erosão dos solos, contaminação de cursos d'água, destruição ou fragmentação de habitats naturais e da vegetação, migrações que, quando localizadas em áreas densamente povoadas, podem resultar em desapropriações para manejo de atividades econômicas (SILVA, 2014).

Diante disso, os líderes de comunidades e bairros junto com a população local buscam, no intuito de garantir a biodiversidade do lago Maicá, a regulamentação da Área de Proteção Ambiental proposta no Plano Diretor do Município, Lei no 18.051/2006, Art.137, inciso VI (SANTARÉM, 2006), denominada APA-Maicá inserida nessa região (SERRÃO, 2018).

Nesse cenário, a agricultura familiar e a pesca artesanal oferecem baixo impacto ao meio ambiente, contribuindo com o equilíbrio do ecossistema, de modo especial na Amazônia. Segundo Chayanov (1966), o processo produtivo de atividades de cunho familiar que tem como finalidade garantir a satisfação das necessidades básicas e o bem-estar dos membros que compõe a família, tem o aumento do esforço produtivo associado a responder as necessidades da sua unidade familiar, evidenciando, assim, uma racionalidade entre produção e consumo.

Dessa forma, a relação de todos os membros da família é elemento essencial para o desenvolvimento das atividades da agricultura familiar e da pesca artesanal. Neste contexto, a mulher assume diferentes funções ao longo da cadeia produtiva, bem como, é a principal responsável pelas atividades domésticas. Quando a análise é realizada levando em consideração a questão de gênero, o quantitativo do total alcança 40\% do contingente de pescadoras artesanais, apesar de ainda ocorrer a invisibilidade do trabalho da mulher nas atividades produtivas (ZHAO; TYZACK; ANDERSON, 2013).

Quando a análise diz respeito à atividade da agricultura familiar, os dados do Censo Agropecuário do IBGE (2009) demonstram que existem aproximadamente 
13,8 milhões de pessoas trabalhando em unidades familiares, o que representa $77 \%$ da população na produção agrícola. Em termos produtivos, existem alguns produtos da agricultura familiar que abastecem o mercado de forma expressiva. Tal prática é responsável por $87 \%$ da produção de mandioca, $70 \%$ do feijão, $46 \%$ do milho, 38\% do café, $34 \%$ do arroz e $21 \%$ do trigo. Na pecuária, essa atividade é responsável por $60 \%$ da produção de leite, 59\% do rebanho suíno, $50 \%$ das aves e $30 \%$ dos bovinos. Ainda de acordo com o censo, a mulher atua como chefe em $12,7 \%$ dos estabelecimentos da agricultura familiar no Brasil.

Diante da presença significativa das mulheres nessas duas atividades econômicas (SOUSA; VIEIRA, 2021), esta pesquisa teve como objetivo descrever as condições socioeconômicas das pescadoras artesanais e agricultoras familiares que residem e exercem suas atividades produtivas na região do lago Maicá, Santarém, Pará, Brasil.

\section{METODOLOGIA}

A pesquisa é descritiva com cunho qualiquantitativo. $\mathrm{Na}$ concepção de Oliveira (2008), a realização da pesquisa quantitativa ajuda a descrever perfis socioeconômicos, como o das pescadoras artesanais e agricultoras familiares participantes do estudo, com o uso de instrumentos de coleta de dados, como questionários, entrevistas, observações e análises técnicas estatísticas. Já a pesquisa qualitativa auxilia na análise das informações coletadas no grupo pesquisado, possibilitando interpretação minuciosa dos fenômenos nos "processos sociais e a interpretação das particularidades dos comportamentos ou atitudes dos indivíduos" (OLIVEIRA, 2008, p. 59).

Para ajudar no aprofundamento dos fenômenos percebidos durante a pesquisa usou-se ainda como aporte metodológico a pesquisa descritiva, que, conforme Gil (2010), auxilia na uniformização no processo de planejamento, coleta e análise dos dados. As técnicas usadas compõem as características do estudo de caso, que contribuiu para realização de um exame detalhado dos fatos. Segundo Yin (2005, p. 34), "o estudo de caso permite uma investigação para se preservar as características holísticas e significativas dos eventos da vida real tais como ciclos de vida individuais, processos organizacionais e administrativos, mudanças ocorridas em regiões urbanas".

O estudo é composto de dados primários e secundários, nesse sentido, os de origem primária foram obtidos em pesquisa realizada in loco com as pescadoras artesanais e agricultoras familiares, com aplicação da metodologia descrita acima. Assim os dados secundários foram levantados por intermédio 
de pesquisa documental e bibliográfica e análise de teses, dissertações, artigos e demais publicações que subsidiaram a compreensão do tema em estudo.

\subsection{CONTEXTUALIZAÇÃO DO ESPAÇO GEOGRÁFICO DA PESQUISA}

O espaço geográfico escolhido para realização da pesquisa foi Santarém, no estado do Pará. A cidade localiza-se à margem direita do rio Tapajós, em posição intermediária às duas maiores metrópoles amazônicas, Belém (PA) e Manaus (AM). Possui uma extensão de $24.154 \mathrm{~km}^{2}$, entre os paralelos $2^{\circ} \mathrm{S}$ e $4^{\circ} \mathrm{S}$ e os meridianos $56^{\circ} \mathrm{W}$ e $54^{\circ} \mathrm{W}$, é uma das cidades que exerce papel importante na dinâmica econômica do estado do Pará, na região Norte do país (RABELO; VAZ; ZACARDI, 2017). Seus primeiros habitantes foram os índios Tupaius que sobreviviam da caça, pesca e da produção agrícola, atividades essas responsáveis pela movimentação da economia local, e que, com o passar dos anos, permanecem sendo desenvolvidas pelas populações tradicionais (agricultores familiares, quilombolas, indígenas, pescadores artesanais entre outros) responsáveis por abastecer o mercado local de alimentos (PMS, 2017).

Conforme o Plano Diretor de Santarém - Lei no 20.534, de 17/12/2018 (SANTARÉM, 2018), a parte urbana da cidade está dividida em cinco zonas, e o local de pesquisa (bairros Maicá e Pérola do Maicá) encontra-se na Zona Leste (formada por 11 bairros). Os bairros estudados estão localizados às margens do lago Maicá, ambiente utilizado para atividades econômicas, como a pesca, atividades domésticas, lazer e turismo (VAZ et al., 2017; SERRÃO, 2018; SOUSA et al., 2020).

Nestas áreas, residem aproximadamente 687 famílias, cerca de 3.149 habitantes (IBGE, 2010), entre os quais estão populações tradicionais (pescadores artesanais, agricultores familiares e quilombolas) e demais pessoas.

\subsection{COLETA DE DADOS}

A coleta de dados ocorreu no período de março a maio de 2018. Inicialmente, reuniu-se, separadamente, com a direção do Sindicato dos Trabalhadores e Trabalhadoras Rurais de Santarém (STTR) e com a Colônia de Pescadores e Pescadoras Z-20 (CPP Z-20) para apresentar o projeto de pesquisa e colher informações preliminares sobre o quantitativo de pescadoras e agricultoras familiares existentes nos bairros escolhidos, bem como obter anuência para realizá-la.

Assim, recolhida a autorização da Colônia de Pescadores Z-20 e da direção do STTR de Santarém e obtido o Parecer Consubstanciado do Comitê de Ética 
em Pesquisa, número 2.452.021, do Instituto Esperança de Ensino Superior (CEP- IESPES), iniciou-se a pesquisa nos bairros Maicá e Pérola do Maicá.

$\mathrm{O}$ critério de inclusão consistiu em pescadoras artesanais e agricultoras familiares associadas em suas entidades sindicais (CPP-20eST'TR respectivamente), moradoras dos bairros Maicá e Pérola do Maicá e que estivessem em pleno exercício de sua atividade produtiva.

Acompanharam-se as reuniões das organizações ligadas ao STTR e a CPP Z-20 com a finalidade de conhecer a rotina organizativa das pescadoras artesanais e agricultoras familiares, além de identificar as mulheres que desenvolvem as atividades produtivas e que são sócias dessas entidades.

Cada participante teve acesso ao Termo de Consentimento Livre e Esclarecido (TCLE), ferramenta pela qual as pescadoras artesanais e agricultoras familiares expressaram seu consentimento para participação da pesquisa. Por meio do termo, a entrevistada declara que foi informada minuciosamente de maneira clara, e por escrito, da justificativa, dos objetivos e dos procedimentos metodológicos usados no estudo.

De acordo com a coordenação do núcleo de base Pérola do Maicá ligado à Colônia de Pescadores Z-20, existiam 19 pescadoras artesanais associadas à organização. Do total, cinco não residiam nos bairros lócus da pesquisa, uma recusou-se a participar, 01 (uma) encontrava-se aposentada e uma não estava exercendo a atividade da pesca há cerca de dois anos. Com o uso dos critérios de inclusão pré-estabelecidos, chegou-se ao número total de 11 pescadoras artesanais.

Quanto ao universo total de agricultoras familiares, a coordenação do STTR possui um cadastro de 20 mulheres sócias que exercem a atividade nos referidos bairros ou em vizinhos. Desse quantitativo, foi possível encontrar nove mulheres nas reuniões da delegacia sindical. Destas, duas agricultoras recusaramse a participar da pesquisa, e sete mulheres aceitaram fazer parte do trabalho, porém não foi possível encontrar as demais (onze) e nem saber se residiam no bairro Maicá ou Pérola do Maicá e se ainda estão na atividade. Sendo assim, o estudo foi realizado com $35 \%$ das agricultoras familiares, representando sete mulheres em número absoluto, seguindo o critério de inclusão pré-estabelecido.

O formulário semiestruturado era composto por perguntas ligadas às questões socioeconômicas das entrevistadas e de suas famílias, à organização social, à importância ambiental do local e à atividade produtiva.

\subsection{ANÁLISE DOS DADOS}

Os dados foram organizados em um banco de dados no programa Excel for $W_{\text {indows }}^{\circledR}$ e analisados por meio de estatística descritiva, com cálculo 
de frequência relativa e obtenção de medida de tendência central (média) e de dispersão dos dados (desvio padrão, 士) (FONSECA; MARTINS, 2008).

No que se refere aos dados econômicos, a pesquisa analisou a composição da renda familiar, usando como parâmetro as principais fontes de rendimento no âmbito rural usadas pela Pesquisa Nacional por Amostra de Domicílios (PNAD), uma vez que as participantes da pesquisa desempenham atividades econômicas (pesca artesanal e agricultura familiar) (BAZOTTI; SUGAMOSTO, 2011). Nesse caso, a pesquisa é composta pela somatória da renda do trabalho das entrevistadas, do cônjuge e dos filhos, incluindo as atividades complementares (quando exercidas) e o valor do benefício social (quando beneficiária).

\section{RESULTADOS E DISCUSSÃO}

\subsection{ASPECTOS SOCIAIS DAS PESCADORAS ARTESANAIS E AGRICULTORAS FAMILIARES}

As pescadoras artesanais possuem idade média de 48,4 ( \pm 8,6) anos, variando de 27 a 57 anos. Do universo total, 54,55\% encontram-se na faixa etária entre 51 e 60 anos, entre as pesquisadas não foi identificada nenhuma pescadora na faixa etária de 31 a 40 anos. Quanto às agricultoras familiares, a média encontrada foi de 46,3 ( \pm 6,4) anos, com variação de 40 a 55 anos. Do universo total 42,86\% estão na faixa de idade entre 41 e 50 anos, não foi encontrada nenhuma agricultora na faixa etária entre 20 e 30 anos (Figura 1).

Figura 1 - Faixa etária das pescadoras artesanais e agricultoras familiares dos bairros Maicá e Pérola do Maicá, Santarém, Pará, Brasil

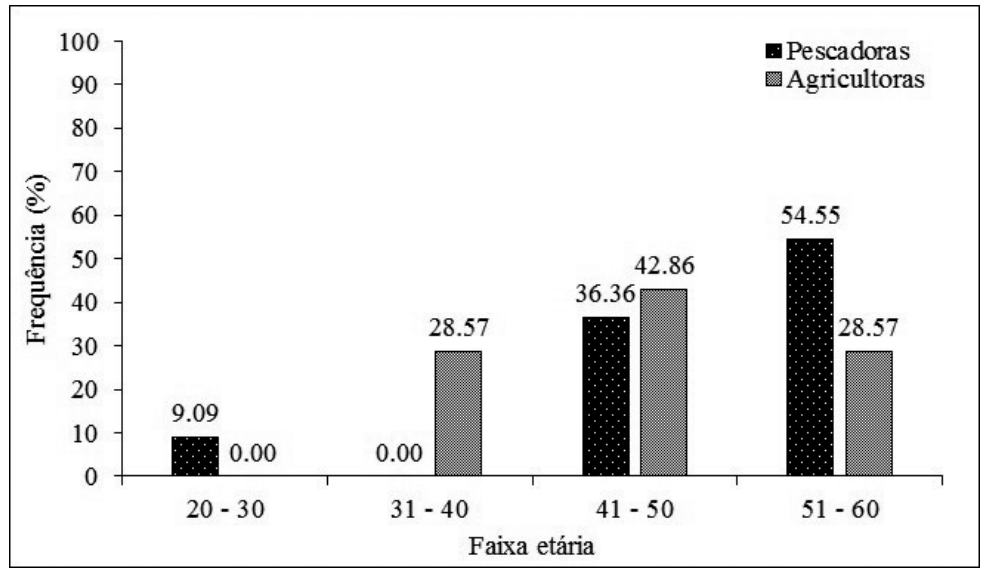

Fonte: elaborado pelos autores com base nos dados da pesquisa. 
De 2005 a 2015, os idosos no Brasil passaram de 9,8\% para 14,3\% da população brasileira, ocorrendo acréscimos em todos os grupos etários de idosos; mas a região Norte possui menor quantitativo $(10,1 \%$ ) e a Sul com $15,9 \%$ (IBGE, 2016). Considerando que no caso do lago Maicá a maioria das mulheres está acima de 41 anos e não tinham se aposentado, pode-se dizer que elas estão em plena capacidade produtiva.

Quanto ao estado civil, percebeu-se que, entre as pescadoras artesanais, a maioria (55\%) vive em união estável, apenas 9\% são casadas no civil e 36\% são solteiras. Já as agricultoras familiares, 43\% declaram ser casadas no civil e o restante vive em união estável (29\%) ou são solteiras (28\%). Entre as entrevistadas não se identificaram viúvas ou que vivessem em união homoafetiva. A estrutura familiar identificada na pesquisa encontrou a tipologia de família tradicional, a qual, para Medeiros e Osório (2001), ocorre na maioria das unidades familiares existente em comunidades rurais, que têm em sua composição homem, mulher e filhos/filhas.

Do total geral das participantes, todas são oriundas do estado do Pará. Dentre as pescadoras artesanais, existe uma variação entre o local de origem, ao passo que 55\% nasceram em comunidades rurais da cidade de Santarém, 18\% no município de Monte Alegre, 18\% em Alenquer e 9\% são de Aveiro, todos na região Oeste do Pará. Tais dados se diferem das agricultoras familiares, onde todas nasceram em comunidades rurais de Santarém.

No que se refere a aspectos religiosos, entre as pesquisadas, a religião católica congrega a maioria (81,8\% pescadoras artesanais e 71,4\% agricultoras familiares), seguida pela evangélica (18,2\% pescadoras artesanais e 28,6\% agricultoras familiares). Na pesquisa realizada por Calegare e Higuchi (2016), no Alto rio Solimões (AM), a religião, juntamente com a prática produtiva e a origem cultural-territorial, contribuiu para a construção de identidades coletivas na referida comunidade rural, ou, conforme Sousa e Vieira (2021), pode influenciar na percepção de mulheres sobre o conceito de qualidade de vida para si, ao viverem em bairros ribeirinhos de Santarém.

Uma característica marcante na realidade estudada diz respeito ao baixo nível de escolaridade das pesquisadas. A grande maioria declarou ter apenas o ensino fundamental incompleto, o que entre as pescadoras artesanais representa 90,9\% (Figura 2a) e 71,4\% entre as agricultoras familiares (Figura 2b). Apesar disso, não foram identificadas participantes analfabetas. Esta realidade do lago Maicá é mais favorável que a de analfabetismo do Pará, para pessoas acima de 60 anos (4,5\% de analfabetos) e para mulheres de áreas urbanas e rurais do Estado que ainda são 5,5\% de analfabetas (IBGE, 2018). 
Figura 2 - Nível de escolaridade das pescadoras (a) e agricultoras (b) e de seus membros familiares dos bairros Maicá e Pérola do Maicá, Santarém, Pará, Brasil
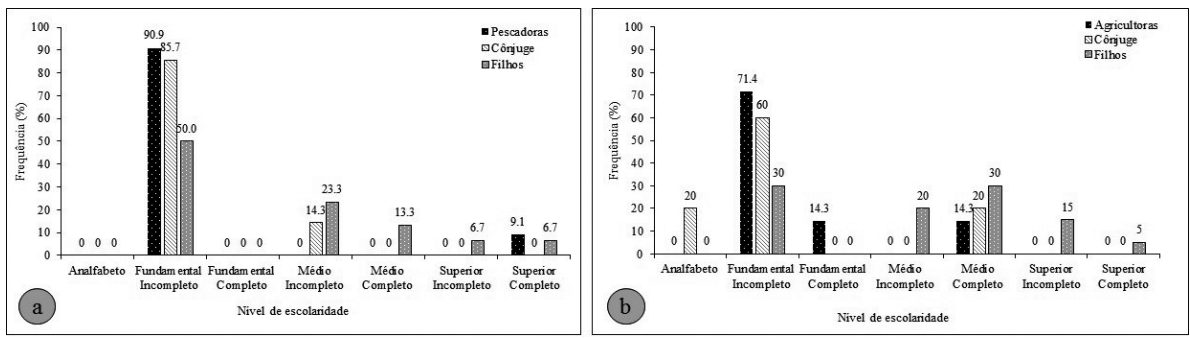

Fonte: elaborado pelos autores com base nos dados da pesquisa.

A pesquisa no lago Maicá identificou ainda o nível de escolaridade dos membros da família (cônjuges e filhos/filhas). Os dados mostraram que a maioria também possui o ensino fundamental incompleto. Ademais entre a família das pescadoras artesanais constatou-se também que 14,3\% do total de cônjuge possui o ensino médio incompleto, e entre os filhos/filhas esse quantitativo representa 23,3\% (Figura 2a).

Quanto à família das agricultoras familiares, 20\% dos cônjuges são analfabetos e este mesmo quantitativo possui o ensino médio completo. Já seus filhos/filhas, $20 \%$ possuem o ensino médio incompleto, $15 \%$ com superior incompleto e 5\% superior completo (Figura 2b).

As pescadoras artesanais e agricultoras familiares cresceram com a necessidade de ajudar seus pais nos trabalhos produtivos familiares para aumentar a renda familiar, o que dificultou o acesso à escola. Na concepção de Nishida (2010), o baixo nível de escolaridade pode ser atribuído ao contexto social e econômico presentes no meio rural. Outro fator que pode ter contribuído para essa realidade é a falta de incentivo dos membros da família e demais pessoas do círculo de relação para continuar os estudos em outras localidades.

Esse cenário é corroborado em relatos por parcela substancial das pesquisadas, quando perguntado o motivo pelo qual elas não continuaram os estudos:

Eu tinha que ajudar nas atividades da comunidade, no cuidado com a juta, a agricultura e a pesca. As escolas da comunidade ofereciam até a $4^{a}$ série do Ensino Fundamental (Pescadora com 55 anos, bairro Maicá).

Eu morava no sítio e a minha mãe tinha dificuldade em me manter na escola que era distante da minha casa, precisava trabalhar para ajudar minha mãe a sustentar a casa (Agricultora com 41 anos, bairro Pérola do Maicá). 
Os discursos mostram também a participação das mulheres, quando jovens, em atividades produtivas. Algo comum, mas que, muitas vezes, não é reconhecido pelos homens e nem pela sociedade. Rompendo as dificuldades encontradas para o acesso à educação, 9,1\% das pescadoras artesanais conseguiram concluir o ensino superior, não sendo essa a mesma condição das agricultoras familiares. Logo, o acesso à educação por membros da família constituía-se uma exceção no meio onde nasceram.

Acerca do tempo de moradia nos bairros, os resultados demonstram que as pescadoras artesanais residem em média há 19 anos $( \pm 9)$ e as agricultoras familiares, em média a 27,3 anos $( \pm 11,6)$. A maioria das participantes da pesquisa declarou ter filhos, e, entre as pescadoras artesanais, a média encontrada é de $4,4( \pm 1,7)$, com uma variação de três a oito filhos. A respeito das agricultoras artesanais, estas apresentaram média de 4,7 filhos $( \pm 2,2)$, variando de dois a oito.

Os dados encontrados quanto à quantidade de filhos, tanto para as pescadoras como agricultoras, estão acima da média nacional que é de 3,1 filhos, apresentada na publicação de Campello e Neri (2013), Instituto de Pesquisa Econômica Aplicada (IPEA). Os resultados evidenciam que a baixa escolaridade pode influenciar na quantidade de filhos gerados pela mulher, dado que se aproxima da afirmação feita por Galúcio (2004), o qual ressalta que as mulheres de nível superior têm em média 1,4 filhos e aquelas que possuem apenas o nível fundamental incompleto têm em média 4,4 filhos, assemelhando-se à realidade vivenciada pelas participantes da pesquisa no lago Maicá.

\subsection{REALIDADE ECONÔMICA DAS PESCADORAS ARTESANAIS E AGRICULTORAS FAMILIARES}

A renda familiar das pescadoras artesanais variou de $\mathrm{R} \$ 300,00$ (trezentos reais) a $R \$ 2.637,00$ (dois mil e seiscentos e trinta e sete reais), com uma média de $\mathrm{R} \$ 1.124,50$ (um mil, cento e vinte quatro reais e cinquenta centavos). Nessa perspectiva, é relevante destacar que 45\% das pescadoras artesanais sobrevivem com menos de um salário-mínimo (época da coleta $\mathrm{R} \$ 954,00$ ). A média de pessoas dependentes dessa renda aproxima-se a quatro indivíduos, com o mínimo de três e o máximo de seis dependentes (Tabela 1). Além do mais, destaca-se que, entre as pescadoras artesanais, 9\% delas não possuem dependes da sua renda familiar. 
Tabela 1 - Perfil econômico das pescadoras artesanais e agricultoras familiares dos bairros Maicá e Pérola do Maicá, Santarém, Pará, Brasil

\begin{tabular}{l|c|c}
\hline \multicolumn{1}{c|}{ Variável } & Pescadoras & Agricultoras \\
\hline Média da Renda Familiar (R\$) & $1.124,50$ & $1.800,30$ \\
\hline Possui Contribuição na Renda Familiar (\%) & 73,0 & 71,4 \\
\hline Quantidade Média de Dependentes & 3,90 & 2,4 \\
\hline Possui Atividade Complementar (\%) & 45 & 42 \\
\hline Crédito Bancário (\%) & 27,3 & 14,3 \\
\hline
\end{tabular}

Fonte: elaborado pelos autores com base nos dados da pesquisa (2018).

A maioria das pescadoras artesanais (55\%) não exerce nenhuma atividade complementar, sendo a pesca o único meio de garantir a sobrevivência de sua família, pois $27 \%$ cultivam produtos da agricultura ou criam pequenos animais para o autoconsumo, e 9\% desenvolvem atividades como costura e o mesmo percentual afirmou realizar serviços de diaristas para ajudar na complementação da renda. Todas as pescadoras artesanais afirmaram que desenvolvem a atividade da pesca há mais de 10 (dez) anos.

Em referência às agricultoras familiares, a renda familiar foi de no mínimo $\mathrm{R} \$ 700,00$ (setecentos reais) e no máximo $\mathrm{R} \$ 3.156,00$ (três mil, cento e cinquenta e seis reais), com média de $\mathrm{R} \$ 1.800,30$ (um mil e oitocentos reais e trinta centavos) (Tabela 1). Destaca-se que 14\% sobrevivem com menos de um salário-mínimo. A média de dependentes dessa renda aproxima-se de 2,4 pessoas, com o mínimo de um e o máximo de cinco dependentes. Além disso, 29\% das agricultoras não possuem nenhum dependente da sua renda familiar.

Importante informar que $14 \%$ das agricultoras declararam que desenvolvem atividade como diarista na região urbana de Santarém, a mesma porcentagem (14\%) afirmou que faz e comercializa produtos de crochê, bem como declararam que realizam venda de cosméticos (14\%) como atividades que ajudam na complementação da renda familiar (Tabela 1). Todas as entrevistadas afirmaram que desenvolvem a atividade de agricultura há mais de 10 (dez) anos.

O desenvolvimento de atividades complementares tem sido chamado no meio científico pela nomenclatura de "pluriatividade", em que os indivíduos que compõem uma família com domicílio rural passam a se dedicar ao exercício de um conjunto variado de atividades econômicas e produtivas, não necessariamente ligadas à agricultura ou ao cultivo da terra, e cada vez menos executadas dentro da unidade de produção (SCHNEIDER, 2003).

Do universo de agricultoras familiares, $57,1 \%$ realizam concomitantemente o cultivo de hortaliças, de plantas frutíferas e a criação de pequenos animais 
(galinhas e patos), 28,6\% realizam apenas duas dessas atividades simultaneamente, o cultivo de hortaliças junto com a criação de pequenos animais ou cultivo de hortaliças junto ao cultivo de plantas frutíferas, 14,3\% das agricultoras realizam somente a criação de pequenos animais.

As áreas de produção destas mulheres são representadas por seus quintais agroflorestais, localizados ao redor de suas casas. Estes sistemas de uso da terra produzem alimentos importantes para subsistência da família (SOUSA et al., 2020; WINKLERPRINS, 2002), como possibilitam trocas de produtos entre seus parentes e ajudam a sustentar redes sociais que subsidiam a vida urbana (WINKLERPRINS, 2002).

Entre as pescadoras artesanais, $73 \%$ possuem ajuda na renda familiar. Dessas, 64\% contam com ajuda de uma pessoa, geralmente o cônjuge, e 9\%, com duas pessoas que correspondem ao cônjuge e um filho. No que se refere às agricultoras familiares, $71,4 \%$ têm ajuda na composição da renda familiar. Destaca-se desse percentual que 57,1\% contam com a ajuda de um membro da família, na maioria dos casos é o cônjuge, e 14,3\% têm ajuda de dois membros da família, o cônjuge e um filho.

Percebeu-se ainda que estas mulheres são beneficiárias do Programa Bolsa Família (PBF), auxílio de substancial importância na composição da renda familiar. Do total das pescadoras artesanais, 63,6\% recebem o benefício, e, das agricultoras familiares, apenas $42,8 \%$ são beneficiárias do programa. Segundo estudos de Cecchin e Parente (2018), o Programa Bolsa Família foi criado com o objetivo de promover o alívio da pobreza por meio da transferência de renda, sendo expressivo o percentual de mulheres beneficiárias deste programa.

Em relação à comercialização, toda a produção da agricultura familiar, assim como da pesca artesanal, é destinada ao autoconsumo e ao abastecimento de feiras, mercados e comércios locais.

\subsection{MORADIA DAS PESCADORAS ARTESANAIS E AGRICULTORAS FAMILIARES}

As pescadoras artesanais e agricultoras familiares que participaram desse estudo são oriundas de comunidades da várzea de Santarém e cidades vizinhas, onde o uso dos recursos naturais, a caça, a pesca e a agricultura são parte do cotidiano. O estudo procurou identificar como as pesquisadas escolheram os bairros onde o estudo foi realizado para residirem. Para as pescadoras artesanais a proximidade do lago Maicá e os fenômenos naturais ocorridos em suas comunidades contribuíram para a escolha do local de moradia. No entanto, 
para as agricultoras familiares a moradia tem relação com aspectos de família, conforme se observa:

Nós viemo pra cá, porque lá onde nós morava caiu a terra, a terra caindo, aí tinha essa área que tavam doando uns terreno e nós viemo pra cá. Não tinha quase ninguém, era só mato, aí nós viemo pra cá que não tinha condição de comprar um terreno [...] tinha dono, agora que a gente tá sabendo. Gosto porque dá acesso ao lago para continuar pescando (Pescadora, reside há 18 anos no bairro).

Justamente porque o Arapemã estava caindo, quando a gente saiu de lá, a nossa casa já tinha mudado, tava praticamente na caída, aí por isso que todo mundo se mudamos pra cá (Pescadora, reside há 21 anos no bairro). Porque meu marido gostava de plantar, aí ele veio e arrumou esse terreno pra cá, e é perto da cidade pra levar (verduras) (Agricultora 2, reside há 32 anos no bairro).

Porque eu gosto do ambiente, gosto daqui, porque esse pedaço aqui é minha família, são meus irmãos (Agricultora 5, reside há 45 anos no bairro).

A região onde vivem essas mulheres possui frágeis condições de infraestrutura local, especialmente quanto ao abastecimento de água e questões ligadas ao saneamento. Ademais, em algumas áreas dos bairros, existem grandes áreas desocupadas, configurando-se como espaços de especulação imobiliária. Os bairros onde as pesquisadas residem estão localizados em uma área periurbana, e que, segundo Lewis (2007, p. 3), “[...] normalmente a área periurbana das cidades Amazônicas tem aspecto rural: agricultura de subsistência, extrativismo da floresta e pesca, as quais proveem alimentos básicos às cidades [...]”.

Sobre a importância da moradia, a maioria das entrevistadas (pescadoras $100 \%$ e agricultoras 86\%) considera a residência como elemento de alta importância em suas vidas, sobretudo porque todas moram em casa própria. A aquisição da residência própria é essencial para que as pescadoras artesanais e agricultoras familiares não vivam em situação de risco de despejos ou ainda sob ameaça de retiradas por ação de terceiros, sendo um dos requisitos do direito à moradia e à promoção da cidadania (IPPUR, 2001).

Ressalta-se que a moradia entendida como um direito é um elemento que possibilita o ingresso a outros benefícios, entre os quais o acesso a saúde, educação, trabalho, acessibilidade, transporte, cultura, lazer, turismo e demais serviços básicos. Além disso, o direito à moradia deve ser entendido no prisma econômico, social, cultural e ambiental, acompanhando os mesmos fundamentos do direito à cidade (SAULE JÚNIOR; CARDOSO, 2005).

Procurou-se analisar a percepção das pesquisadas quanto à importância que o bairro desempenha em suas vidas. Assim, percebeu-se que a maioria 
considera um elemento importante. Destaca-se que isto foi observado em 91\% das pescadoras artesanais, as quais residem nesse mesmo local, em média há 19 anos. Quanto às agricultoras familiares, 86\% consideram um elemento importante, haja vista que residem, em média, há 27,3 anos no mesmo local.

No que concerne às condições habitacionais das pesquisadas, constatouse que $100 \%$ possuem casa própria e a maioria tem acesso à energia elétrica (pescadoras artesanais $86 \%$ e agricultoras familiares $88,89 \%$ ). Esse serviço nas residências permite aquisição do conhecimento de forma geral por intermédio dos diversos meios de comunicação, além do uso de eletrodomésticos (fogão, geladeira, liquidificador entre outros) e demais equipamentos, na rotina doméstica ou para agregar valor a seus produtos ou verticalizar a produção (SOUZA; ANJOS, 2007).

Quanto à estrutura das moradias, 57\% das pescadoras artesanais e 45\% das agricultoras familiares possuem casas de alvenaria, além disso, existem ainda as residências em estrutura mista - madeira e alvenaria - (29\% pescadoras artesanais e $27 \%$ das agricultoras familiares) e o restante com estrutura de madeira.

A respeito do lixo doméstico, existe uma diferença no método usado para a destinação final dos resíduos produzidos. Das pescadoras artesanais, 57\% declararam que os resíduos produzidos são queimados, 29\% afirmaram que os resíduos são destinados à coleta pública e 14\% usam os métodos anteriores conjuntamente. As agricultoras familiares asseguraram que 55\% depositam o resíduo doméstico na coleta pública, 36\% declararam que destinam à coleta pública ou queimam os resíduos e $9 \%$ confirmaram que apenas queimam os resíduos (Figura 3).

A queima do lixo é danosa ao meio ambiente, principalmente por liberar gases nocivos à atmosfera e por poder provocar incêndios na vegetação. A proibição do uso do fogo visando proteger a vegetação está disciplinada no Código Florestal Brasileiro, Lei no 12.651, de 25 de maio de 2012 (BRASIL, 2012). Sob esse prisma, mostra-se evidente a necessidade de desenvolver políticas públicas, entre outras atividades, não somente no sentido de preservar, mas também de identificar a melhor maneira de conjugar o binômio utilização/ conservação dos recursos naturais e o aumento da produtividade na propriedade rural (ROCHA et al., 2012).

Um fato que chama atenção na pesquisa refere-se à questão de esgotamento sanitário: $28,6 \%$ das pescadoras e $27 \%$ das agricultoras declararam que em suas residências utilizam uma forma rudimentar para destinação dos dejetos produzidos em suas casas, como a fossa negra (Figura 3). Como os bairros não possuem estrutura e ações de políticas públicas adequadas para coleta dos dejetos, 
as entrevistadas acabam fazendo o despejo de forma inadequada, o que pode contaminar os lençóis freáticos e agredir o meio ambiente. Realidade vivenciada na maioria dos bairros, o que demonstra a semelhança com comunidades rurais de modo especial da várzea onde “[...] comunidades não dispõem de estrutura básica de ensino médio, posto de saúde e possuem abastecimento precário de água, bem como de saneamento" (MARTINS, 2009, p. 63).

Figura 3 - Situação habitacional de pescadoras e agricultoras familiares dos bairros Maicá e Pérola do Maicá, Santarém, Pará, Brasil
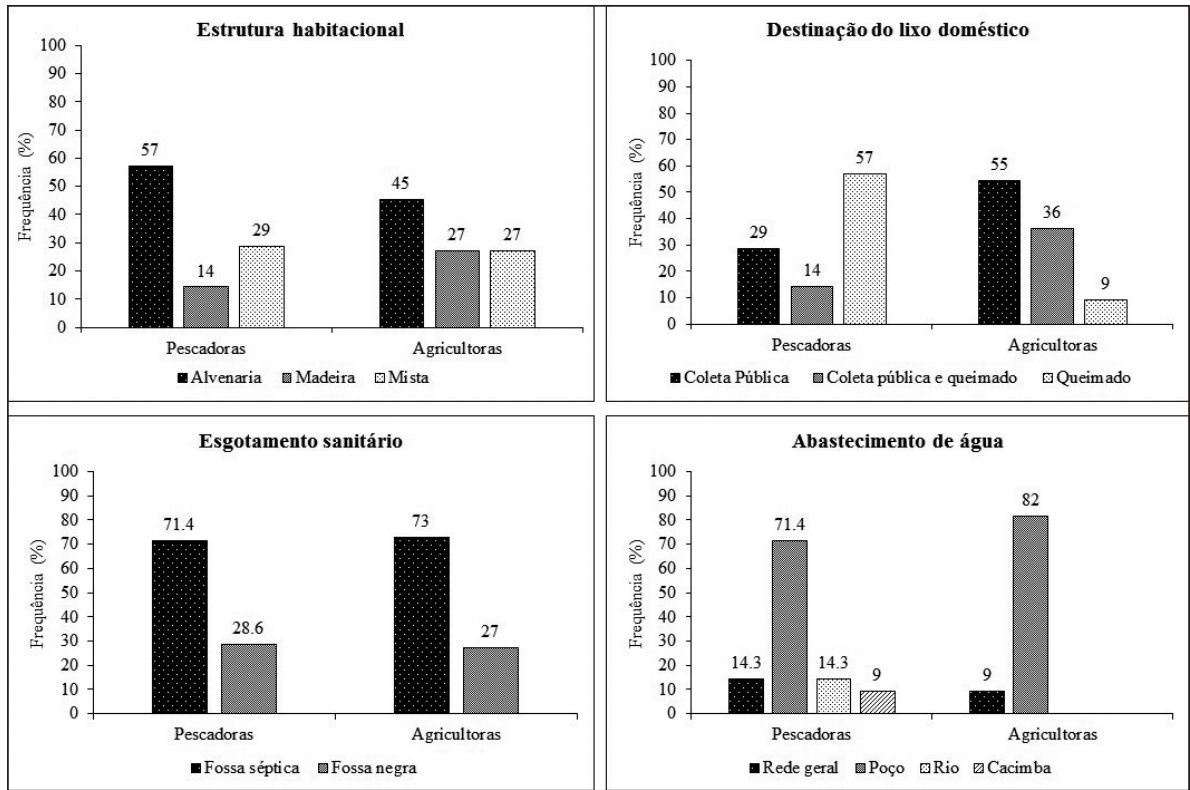

Fonte: elaborado pelos autores com base nos dados da pesquisa.

Quanto ao serviço de abastecimento de água, percebe-se que a maioria das pesquisadas abastece suas casas com água proveniente de poços nas residências e um percentual pequeno (14,3\% pescadoras artesanais e $9 \%$ de agricultoras familiares) tem acesso à rede geral de distribuição de água, que consiste em microssistema dos bairros. Além disso, 14,3\% das pescadoras artesanais fazem a captação de água para consumo e uso doméstico direto do lago Maicá e 9\% usam a cacimba para suprir suas necessidades de acesso à água (Figura 3).

O Plano Diretor da cidade de Santarém destaca ser de responsabilidade do Poder Público Municipal a limpeza urbana, incluindo a disposição final de resíduos sólidos (Art. 56), o acesso ao sistema de coleta e tratamento final dos esgotos (Art. 66) e a possibilidade de ser responsável pelo abastecimento de água potável ao consumo humano (Art. 63) (SANTARÉM, 2018). No entanto, 
a realidade detectada durante a pesquisa revela o estado de vulnerabilidade a que as famílias residentes desses espaços urbanos estão submetidas, nesse caso específico, as pescadoras artesanais e agricultoras familiares.

Devido essa realidade ser frequente em muitos lugares do Brasil, Siliprandi e Cintrão (2011) alertam sobre a carência de acesso aos recursos básicos, como: água, energia elétrica, esgotamento sanitário e tantos outros que acometem muitos brasileiros, mas, especialmente, as mulheres, uma vez que são elas as responsáveis diretas pelos afazeres domésticos e o bem-estar familiar.

\section{CONCLUSÃO}

A participação das mulheres na pesca artesanal e na agricultura familiar é de extrema importância para o desenvolvimento econômico local. Além disso, exercem fundamental influência na qualidade de vida dessas mulheres e de suas famílias que extrapola o valor econômico e social, alcançando um valor cultural e simbólico, que garante a produção para o autoconsumo e a comercialização dos produtos excedentes. Possuem produção significativa, porém têm acesso a poucos locais para comercializar seus produtos, estando limitadas ao local onde residem, aos bairros próximos e/ou feira, onde o preço pago pelos produtos é muito baixo, e, na tentativa de complementar a renda familiar, exercem outras atividades esporadicamente.

As pescadoras artesanais e agricultoras familiares vivem em ambientes semelhantes ao cenário habitacional e social, com fragilidades em relação ao acesso às políticas públicas de saneamento básico, ao abastecimento de água e à educação.

Este estudo auxilia na discussão de políticas públicas que ajudem a mitigar as dificuldades enfrentadas no cotidiano dessas mulheres e suas famílias. Serve ainda de aporte teórico para a temática pesquisada, para entidades sindicais e participantes da pesquisa, visando fornecer subsídios ao debate sobre modelos de desenvolvimento que garantam a sobrevivência dessas mulheres em suas unidades familiares, sobretudo em ambientes e ecossistemas frágeis, como o caso da várzea.

\section{REFERÊNCIAS}

BATISTA, V. S.; ISAAC, V. J.; VIANA, J. P. Exploração e manejo dos recursos pesqueiros da Amazônia. In: RUFFINO, M. L. (org.). A pesca e os recursos

pesqueiros da Amazônia brasileira. Manaus: IBAMA/ProVárzea, 2004. p. 63-151. 
BAZOTTI, A.; SUGAMOSTO, M. Renda das Famílias Rurais Paranaenses: uma análise exploratória. Cadernos IPARDES, Curitiba, v. 1, n. 2, p. 45-61, 2011. BRASIL. Lei $\mathbf{n}^{\mathbf{0}} \mathbf{1 2 . 6 5 1}$, de 25 de maio de 2012. Dispõe sobre a proteção da vegetação nativa [...]. Brasília, DF: Presidência da República, [2012]. Disponível em: http://www.planalto.gov.br/ccivil_03/_ato2011-2014/2012/lei/112651. htm. Acesso em: 10 mar. 2013.

CALEGARE, M. G. A.; HIGUCHI, M. I. G. Transformações das Identidades Coletivas em Comunidade no Alto Solimões/AM. Psicologia: teoria e pesquisa, Brasília, DF, v. 32, n. 3, p. 1-9, 2016. DOI: http://dx.doi. org/10.1590/0102-3772e323222.

CAMPELlO, T.; NERI, M. C. (org.). Programa Bolsa Família: uma década de inclusão e cidadania. Brasília, DF: IPEA, 2013. Disponível em: https://www.ipea.gov.br/portal/images/stories/PDFs/livros/livros/livro_ bolsafamilia_10anos.pdf. Acesso em: 10 jul. 2017.

CECCHIN, H. F. G.; PARENTE, T. G. Diversas vozes, muitos dilemas: discutindo o Programa Bolsa Família a partir das questões de gênero e empoderamento. Desenvolvimento em Questão, Ijuí, v. 16, n. 43, p. 322-352, 2018. DOI: https://doi.org/10.21527/2237-6453.2018.43.322-352.

CHAYANOV, A. V. On the theory of non-capitalist economic systems. Clásicos y Contemporáneos en Antropología, [s. l.], p. 1-28, 1966.

DELGADO, N. G. Desenvolvimento local e extensão rural e pesqueira. Estudos Sociedade e Agricultura, Rio de Janeiro, v. 16, p. 62-73, 2001.

FONSECA, J. S.; MARTINS, G. A. Curso de estatística. São Paulo: Atlas. 2008. FURTADO, L. G. Caracteriśticas gerais e problemas da pesca amazônica no Pará. Boletim do Museu Paraense Emílio Goeldi, Belém, v. 6, n. 1, p. 41-93, 1990.

GALÚCIO, D. M. R. Amazônia: pescadores contam histórias. Santarém: IBAMA: PróVárzea, 2004. 134 p. (Coleção Retrato Regional).

GIL, A. C. Como elaborar projetos de pesquisa. 5. ed. São Paulo: Atlas, 2010. IBGE. Censo agropecuário 2006: Brasil, grandes regiões e Unidades da Federação. Rio de Janeiro: IBGE, 2009. 777 p. Disponível em: https://biblioteca. ibge.gov.br/visualizacao/periodicos/51/agro_2006.pdf. Acesso em: 20 jul. 2018. IBGE. SIDRA - Sistema IBGE de Recuperação Automática. IBGE, Rio de Janeiro, 2010. Disponível em: https:/ / sidra.ibge.gov.br/acervo\#/S/Q. Acesso em: 02 jul. 2021. 
IBGE. Síntese de indicadores sociais: uma análise das condições de vida da população brasileira - 2016. Rio de Janeiro: IBGE, 2016. 146 p. Disponível em: https://biblioteca.ibge.gov.br/visualizacao/livros/liv98965.pdf. Acesso em: 21 jun. 2021.

IBGE. Pesquisa Nacional por Amostra de Domicílios: taxa de analfabetismo - Pará. Rio de Janeiro: IBGE, 2018. Disponível em: https:/ /www.ibge.gov. br/estatisticas/sociais/populacao/9171-pesquisa-nacional-por-amostra-dedomicilios-continua-mensal.html?=\&t=downloads. Acesso em: 21 jun. 2021.

IPPUR. Política Municipal de Habitação: orientações para formulação e implementação. Rio de Janeiro: IPPUR, 2001. (Cadernos do Programa, v. 1).

LEWIS, J. Identidade e a região peri-urbana de Belém do Pará: lições para o investimento de desenvolvimento municipal. [S. l.: s. d.], 2007. 14 p. Disponível em: https://projects.ncsu.edu/project/amazonia/brazil_proj/ Result/Identidade_Regiao_PeriUrbana_Lewis.pdf. Acesso em: 21 jun. 2021. MARTINS, E. V. Dinâmica da economia e das relações do trabalho da pesca artesanal no município de Santarém. 2009. 105 f. Dissertação (Mestrado em Planejamento do Desenvolvimento) - Programa de PósGraduação em Desenvolvimento Sustentável do Trópico Úmido, Núcleo de Altos Estudos Amazônicos, Universidade Federal do Pará, Belém, 2009.

MEDEIROS, M.; OSORIO, R. Arranjos domiciliares e arranjos nucleares no Brasil: classificação e evolução de 1977 a 1988. Rio de Janeiro: IPEA, 2001. (Texto para discussão, 788).

MORENO, C. O. Brasil made in China: para pensar as reconfigurações do capitalismo contemporâneo. São Paulo: Fundação Rosa Luxemburgo. 2015.

NISHIDA, A. K. Catadores de moluscos do litoral Paraibano: estratégias de subsistência e formas e percepção da natureza. 2010. 143 f. Tese (Doutorado em Ecologia e Recursos Naturais) - Programa de Pós-Graduação em Ecologia e Recursos Naturais, Universidade Federal de São Carlos, São Carlos, 2010.

OLIVEIRA, M. M. Como fazer pesquisa qualitativa. 2. ed. Petrópolis, RJ: Vozes, 2008. 184 p.

PMS. Histórico de Santarém. Prefeitura Municipal de Santarém, Santarém, 2017. Disponível em: http:/ /www.santarem.pa.gov.br/conteudo/ ?item $=121 \& \mathrm{fa}=60$. Acesso em: 10 jul. 2018

RABELO, Y. G. S.; VAZ, E. M.; ZACARDI, D. M. Perfil Socioeconômico dos Pescadores Artesanais de dois Lagos Periurbanos de Santarém, Estado do Pará. Revista Desafios, Palmas, v. 4, p. 73-82, 2017. http://dx.doi.org/10.20873/ uft.2359-3652.2017v4n3p73. 
ROCHA, A. C.; CERET'TA, G. F.; BOT'TON, J. S.; BARUFFI, L.; ZAMBERLAN, J. F. Gestão de resíduos sólidos domésticos na zona rural: a realidade do município de Pranchita - PR. Revista Administração, São Paulo, v. 5, p. 699-714, 2012.

SANTARÉM. Lei $\mathbf{n}^{\circ}$ 18.051, de 29 de dezembro de 2006. Institui o Plano Diretor Participativo do Município de Santarém. Santarém: Prefeitura Municipal de Santarém, [2006]. Disponível em: https://sapl.santarem.pa.leg.br/media/sapl/ public/normajuridica/2006/43/43_texto_integral.pdf. Acesso em: 18 jun. 2021.

SANTARÉM. Lei $\mathbf{n}^{\circ}$ 20.534, de 17 de dezembro de 2018. Institui o Plano Diretor Participativo do Município de Santarém. Santarém: Prefeitura Municipal de Santarém, [2018]. Disponível em: https://sapl.santarem.pa.leg.br/media/ sapl/public/normajuridica/2018/1610/lei_n_20_534_de_17_12_2018_plano_ diretor_participativo.pdf. Acesso em: 18 jun. 2021.

\section{SAULE JÚNIOR, N.; CARDOSO, P. M. O Direito à Moradia no Brasil:} violações, práticas positivas e recomendações ao governo brasileiro. São Paulo: Instituto Polis, 2005.

SCHNEIDER, S. Teoria Social, agricultura familiar e pluriatividade. Revista Brasileira de Ciências Sociais, [s. l.], v. 18, p. 99-122, 2003.

SERRÃO, E. M. A pesca e o conhecimento tradicional dos pescadores de um lago de inundação no Baixo Amazonas: sugestões para manejo e conservação. 2018. 106 f. Dissertação (Mestrado em Recursos Aquáticos Continentais Amazônicos) - Programa de Pós-Graduação em Recursos Aquáticos Continentais Amazônicos, Universidade Federal do Oeste do Pará, Santarém, 2018.

SERRÃO, E. M.; BRAGA, T. M. P.; COÊLHO, Y. K. S.; CAMPOS, D. P. F; SANTOS, A. A. S.; IMBIRIBA, L. C.; ZACARDI, D. M. Conhecimento tradicional dos pescadores sobre o comportamento reprodutivo dos peixes em um lago de inundação no Oeste do Pará, Brasil. Sociedade \& Natureza, Uberlândia, v. 31, n. 1, p. 1-21, 2019. DOI: http://dx.doi.org/10.14393/SN-v31-2019-45133.

SILIPRANDI, E.; CINTRÃO, R. As mulheres agricultoras no Programa de Aquisição de Alimentos (PAA). Segurança Alimentar e Nutricional, Campinas, v. 18, n. 2, p. 1-21, 2011. DOI: https://doi.org/10.20396/san.v18i2.8634675.

SILVA, Y. A. R. Agricultura mecanizada e expansão urbana em SantarémPA: padrões e processos espaciais. 2014. 73 f. Trabalho de Conclusão de Curso (Graduação em Licenciatura Plena em Geografia) - Faculdade de Geografia, Universidade Federal do Oeste do Pará, Santarém, 2014. 
SOUSA, W. L.; VIEIRA, T. A. An Amazonian Lake and the quality of life of its women: the case of Maicá, Santarém, Brazil (2018). Environment, Development and Sustainability, [s. l.], v. 23, 2021. DOI: https://doi. org/10.1007/s10668-021-01486-x.

SOUSA, W. L.; SANTOS, A. O.; SERRÃO, E. M.; GAMA, A. S. P.; VIEIRA, T. A. Quintais agroflorestais e trabalho da mulher em espaço periurbano: um estudo de caso em Santarém, Pará, Brasil. Research, Society and Development, [s. l.], v. 9, n. 12, p. e8691210792, 2020. DOI: 10.33448/rsd-v9i12.10792.

SOUZA C. R. G; ANJOS F. S. Impacto dos programas de eletrificação rural em comunidades rurais de Arroio Grande, RS. Revista Extensão Rural, Santa Maria, v. 14, p. 37-63, 2007.

VAZ, E. M. Caracterização da atividade pesqueira praticada no Lago Maicá, Município de Santarém, Pará. 2016. 49 f. Trabalho de Conclusão de Curso (Bacharelado de Engenharia de Pesca) - Faculdade de Engenharia de Pesca, Universidade Federal do Oeste do Pará, Santarém, 2016.

VAZ, E. M.; RABELO, Y. G. S.; CORRÊEA, J. M. S.; ZACARDI, D. M. A pesca artesanal no lago Maicá: aspectos socioeconômicos e estrutura operacional.

Biota Amazônia, Macapá, v. 7, p. 6-12, 2017.

VIEIRA, J. C. Quilombolas na cidade: dilemas do planejamento urbano frente ao território do quilombo do Maicá em Santarém-Pará. In: ENCONTRO NACIONAL DO CONSELHO NACIONAL DE PESQUISA E PÓSGRADUAÇÃO EM DIREITO, 22., 2013, Curitiba. Anais [...]. Curitiba: CONPEDI, 2013. p. 1-30. Disponível em: http://www.publicadireito.com.br/ artigos $/$ ?cod $=6$ f8805c87ad80ed9. Acesso em: 15 jul. 2018.

WINKLERPRINS, A. M. House-lot gardens in Santarém, Pará, Brazil: Linking rural with urban. Urban Ecosystems, [s. l.], v. 6, p. 43-65, 2002. DOI: https:// doi.org/10.1023/A:1025914629492.

YIN, R. K. Estudo de caso: planejamento e métodos. 3. ed. Porto Alegre: Bookman, 2005. 212 p.

ZHAO, M.; TYZACK, M.; ANDERSON, R. Estera Onoakpovike. Women as visible and invisible workers in fisheries: A case study of Northern England. Marine Policy, [s. l.], v. 37, p. 69-76, 2013. DOI: http://dx.doi.org/10.1016/j.marpol. 